\title{
INTEGRATION OF SATELLITE, GIS, AND GAMMA-SPECTROMETRIC ANALYSIS DATA TO STUDY THE DISTRIBUTION OF MOBILE PHOSPHORUS IN GRAY FOREST SOILS
}

\author{
DOI: https://doi.org/10.18509/GBP210523t
}

UDC: 546.18:630.114]:[528.46.02:004(470+571)

\author{
Lubov Trofimetz ${ }^{1}$ \\ Evgeny Panidi \\ ${ }^{1}$ Orel State University named after I.S. Turgenev, Russia \\ ${ }^{2}$ Saint Petersburg State University, Russia
}

\begin{abstract}
Estimation of P2O5 (mobile phosphorus) distribution in the arable soil layer is significant when planning effective application of phosphorous fertilizers. Additionally, it is necessary to understand soil erosion impact onto the $\mathrm{P} 2 \mathrm{O} 5$ variability in soil material. We conduct our study in the experimental area located in the basin of Sukhaya Orlitsa River (European part of Russia, Orel region, Orel district). The territory belongs to the periglacial zone of the Russian plain, where the paleocryogenic landforms are presented (block elevations, inter-block depressions of watershed surfaces, ravine complexes on the slopes). The paleocryogenic microrelief is clearly visible on very high resolution satellite imagery. Chernobyl origin caesium-137 acts as a marker of washed gray forest soils, and makes it possible to estimate a soil washout degree. The study is aimed onto design of GIS-based methodology for estimation of washout and redistribution of the soil material and its components.

The use of $0.5-1 \mathrm{~m} /$ pix satellite imagery, GIS-based representation and analysis (GIS is a Geographic Information System), gamma-spectrometric and agrochemical analyses allowed us to draw the following conclusions. In poorly washed soils in block elevations and watersheds of micro-ravines a caesium-137 reserve in under-plowing soil layer (layer under 24-25 cm) does not exceed 4-10\%. Mobile phosphorus content in the arable soil layer in these areas is low (less than $8 \mathrm{mg} / 100 \mathrm{~g}$ ). It can be explained by the repeated plowing and moving of soil on the blocks and watersheds of micro-ravines, reduced soil moisture, and low content of organic material in the soil (humus content is less than 4\%). Additionally, we made a number of experiments confirmed that the content of mobile phosphorus in the arable soil layer of micro-ravine thalwegs is higher than in watersheds (for washed and washed/washed-in soils). Our hypothesis assumes that in wet plowing furrows and micro-ravines the remains of agricultural plants are buried and decomposed (humus content here is more than 4\%). Consequently, the phosphoric acid compounds are accumulated in the arable horizon of thalwegs, and P2O5 content here reaches 15-21 $\mathrm{mg} / 100 \mathrm{~g}$.
\end{abstract}

Keywords: Soil Runoff, Surface Erosion, Radiocesium Method, Arable Horizon, Soil Sampling

\section{INTRODUCTION}

Effective use of phosphorus fertilizers assumes an understanding of the soil erosion impact onto the variability of P2O5 (mobile phosphorus) content in the soil material of arable layer. Additionally, understanding of a picture of its spatial distribution is 
necessary when formalizing recommendations on the of phosphorus fertilizers application in specific area. It is known that within area of grey forest soils large volume of fertilizers (in the cases of their systematic application) lead to the phosphorus reserve exceeding of $15 \mathrm{mg}$ per $100 \mathrm{~g}$ of the soil material. However, in the conditions of eroded soils phosphorus reserve decreases.

It is known also that Chernobyl origin caesium-137 can be applied as a marker of soil washout degree. Washed soils are characterized by reduced value of specific radioactivity of caesium-137. This effect is produced because of the erosion and decrease of the upper (arable) soil layer, while plowing brings up the material of the lower soil layer that is not contaminated with caesium. As a result, the radioactivity of the integral soil sample is lower in comparison to the unwashed soils. So, the caesium-137 marks the arable soil layer due to its non-exchangeable absorption by the soil material and (in fact) absence of its vertical migration through the soil layer (while mobile phosphorus is redistributed along the soil profile).

Mapping of the lateral distribution of caesium-137 and mobile phosphorus and estimation of the dependencies between distribution of mobile phosphorus and radioactivity of caesium-137 have to make possible an assumption on erosion processes influence onto the phosphorus state of grey forest soil.

\section{DATA AND METHODS}

The work is based upon the data of experimental studies conducted in 2016-2019 on the agricultural area located in the Oryol district of the Oryol region, in the basin of the Sukhaya Orlitsa River (52 $\left.59^{\prime} \mathrm{N}, 35^{\circ} 57^{\prime} \mathrm{E}\right)$. The area is located in periglacial zone of the Russian Plain, where the paleocryogenic landforms are presented widely (block elevations and inter-block depressions on the watershed surfaces, ravines on the slopes) [8].

We attracted very high resolution satellite imagery (available publically on the Google Earth - https://www.google.com/earth/) to detect and verify detection of such paleocryogenic landforms, as on open arable areas these landforms can be detected visually basing on differences in soil moisture and consequent differences in its color in the satellite image. Satellite imagery were used in combination with topography survey data analysis to detect the landforms.

Chernobyl origin caesium-137 was used as a marker of washout degree of gray forest soil. Data of agrochemical and gamma-spectrometric analysis of soil samples collected in the area allowed us to gain some insights about the possibilities and limitations that appear when applying caesium-137 to estimate content of mobile phosphorus in the arable soil layer. Soil sampling was conducted using layer-by-layer and integral techniques in a 0-25 cm layer. Data were combined and mapped in the ArcGIS for desktop software (https://www.esri.com/en-us/arcgis/products/arcgis-desktop/overview).

\section{RESULTS AND DISCUSSION}

Figure 1 shows locations of soil sampling points mapped onto a fragment of a satellite image. The area is covered by arable field and located on the slope of the southern exposure. Content of mobile phosphorus in the arable layer $(0-25 \mathrm{~cm})$ was estimated basing on the agrochemical analysis of collected samples. It can be seen that several zones can be allocated in the area basing on surface vertical curvature [2] and values of mobile phosphorus content. Zone \#2 is located on the watershed surface. It is characterized by 
low values of P2O5 in the arable layer (6.2-7.2 $\mathrm{mg}$ per $100 \mathrm{~g}$ of soil material). These soils can be recognized as plowed-eroded medium-cultivated. The flat watershed surface is easier for plowing and can be plowed deeper, consequently the humus is mineralized [3]. The humus content in this soil material is less than $4 \%$. The low content of mobile forms of the phosphorus in the soil material of watershed surface by can be explained both by their removal through the crop harvesting and by soil erosion processes.

Zone \#4 is located down the slope. P2O5 volume increases here and reaches $20.6 \mathrm{mg}$ per $100 \mathrm{~g}$ of soil material. The slope is corrupted by erosion furrows. It is not recommended to apply phosphorus fertilizers in this part of the slope. Increase of soil fertility in this erosive zone can be explained by that the nutrients are brought here with washed-in soil from the above-located areas.

There is a slight decrease in $\mathrm{P} 2 \mathrm{O} 5$ content in the zone \#5, but it remains 1.5-2 times higher than on the watershed surface. For this zone, the inverse interdependence of mobile phosphorus and caesium-137 radioactivity is detected (Fig. 2). This dependence can be explained as follows. In the washed soils of the ravines, content of caesium-137 decreases, and P2O5 remains high due to introduction of washed in soil material alongside with phosphoric acid compounds from the upper slopes.

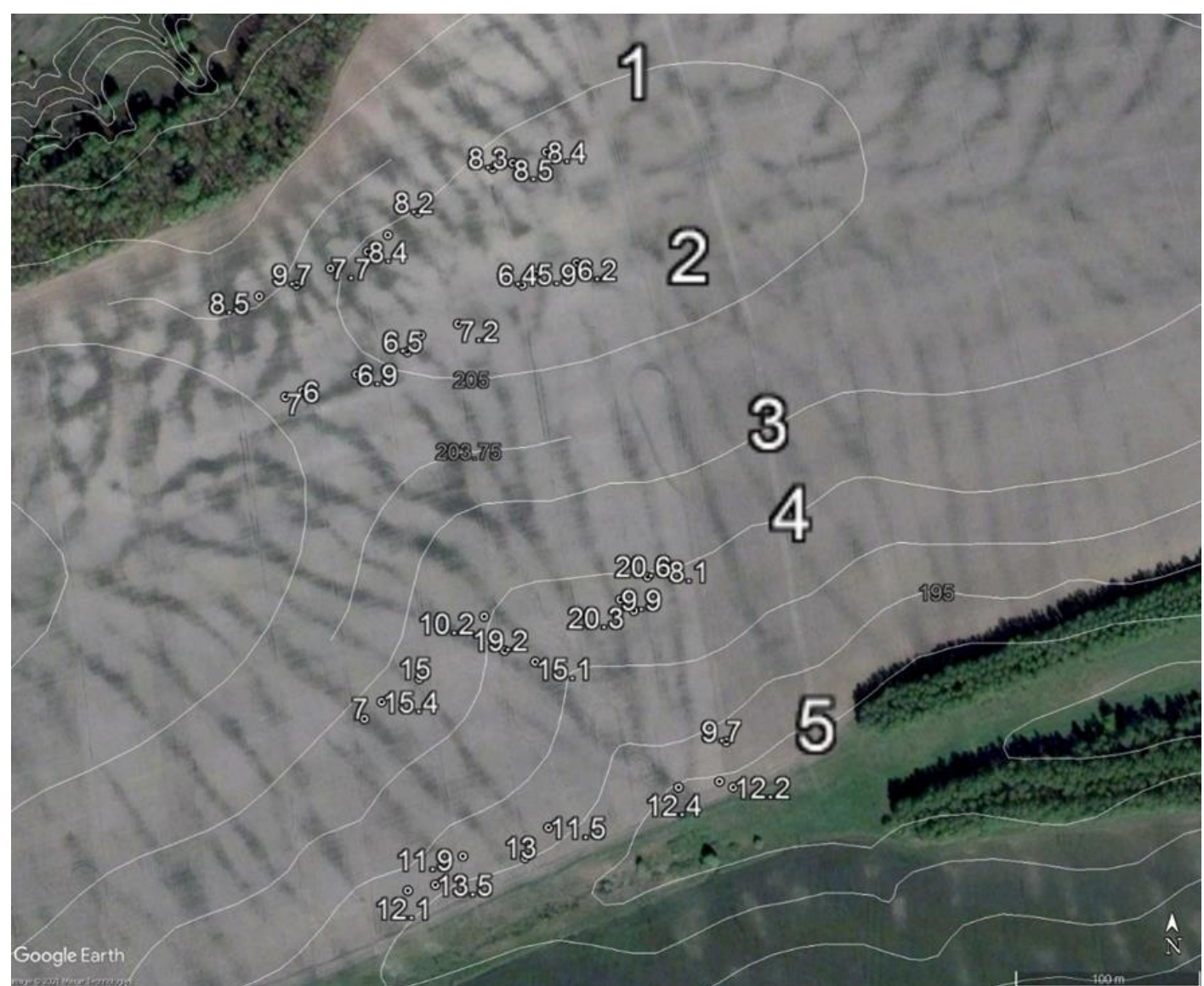

Figure 1. Zones (1-5) of the southern exposure slope, allocated accordingly to the mobile phosphorus content in the soil material (phosphorus content in $\mathrm{mg}$ per $100 \mathrm{~g}$ of soil material is marked by labeled marks of soil sampling points)

Zones \#1 and \#2 located on the watershed surface are interesting to be estimated for the common behavior of caesium-137, humus, and mobile phosphorus. Soil samples were collected here using layer-by-layer collection technique (per $2 \mathrm{~cm}$ ) in 2017. Figure 3 
shows that the sampling points were located in block elevations, in inter-block depressions, and in thalweg of the plowing furrow.

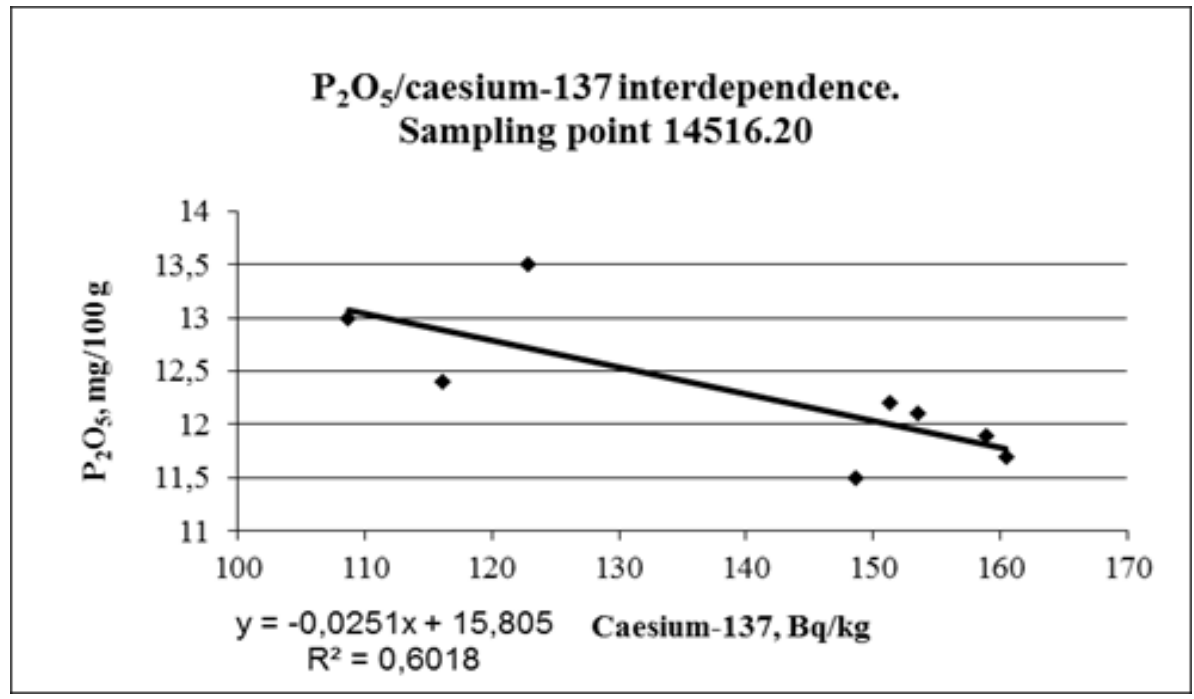

Figure 2. Interdependence of mobile phosphorus and caesium-137 radioactivity in zone \#5 (accordingly to the Figure 1)

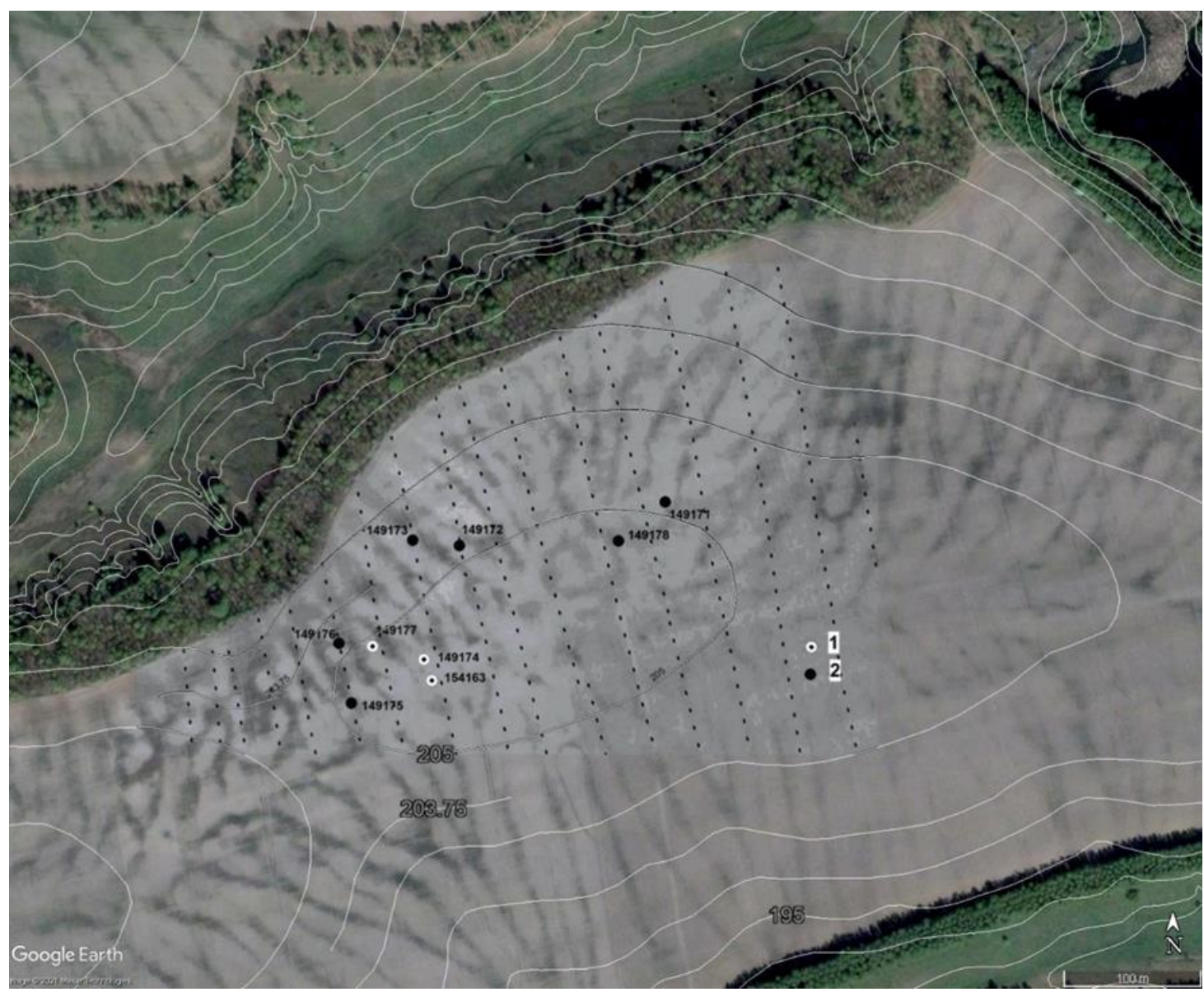

Figure 3. Soil sampling points ( 1 - samples to determine reference value of caesium-137 radioactivity, 2 - other sampling points); dotted lines represent locations of the plowing furrows in 2014; point 149171 is located in plowing furrow of 2003 (it is detected as a barely discernible light strip in the satellite image) 
The very high resolution satellite image (Fig. 3) shows that the heterogeneity of the watershed surface is caused by paleocryogenic origin block elevations and inter-block depressions [1, 5-7]. Impact of paleocryogenic origin microrelief onto the erosion processes we considered in previous publications [6]. We showed that increased values of the caesium-137 specific radioactivity are confined to the unwashed or weakly washed soils of block elevations or to the micro-watersheds located between ravines on the slope. The humus volume in these areas is reduced due to the nutrients removal with the crop phytomass and the mineralization of humus. In conditions of deep plowing, the seeds are shown to a greater depth, and the yield is increased. All these lead to humus reserve decrease in arable layer.

Soil sampling was made layer-by-layer in the watershed area (Fig. 3) in order to detect differences between mobile phosphorus distribution on the depth of the arable soil layer of unwashed soils in block elevations, and of the washed/washed-in soils in inter-block depressions. Sampling points (numbered as 149171, 149172, 149173, 149174, 149175, 149176, 149177, 149178) were located both in the block elevations (light areas in satellite image) and in the inter-block depressions (dark areas), 400 samples were analyzed in whole. Each sample was subjected to gamma-spectrometric and agrochemical analyses (caesium-137 radioactivity, humus volume, soil acidity, mobile phosphorus content were determined).

Diagrams of the caesium-137, humus, and mobile phosphorus on depth distribution (Fig. 4-6) were plotted. These diagrams helped to detect a number of features of the caesium137, humus, and mobile phosphorus distribution.
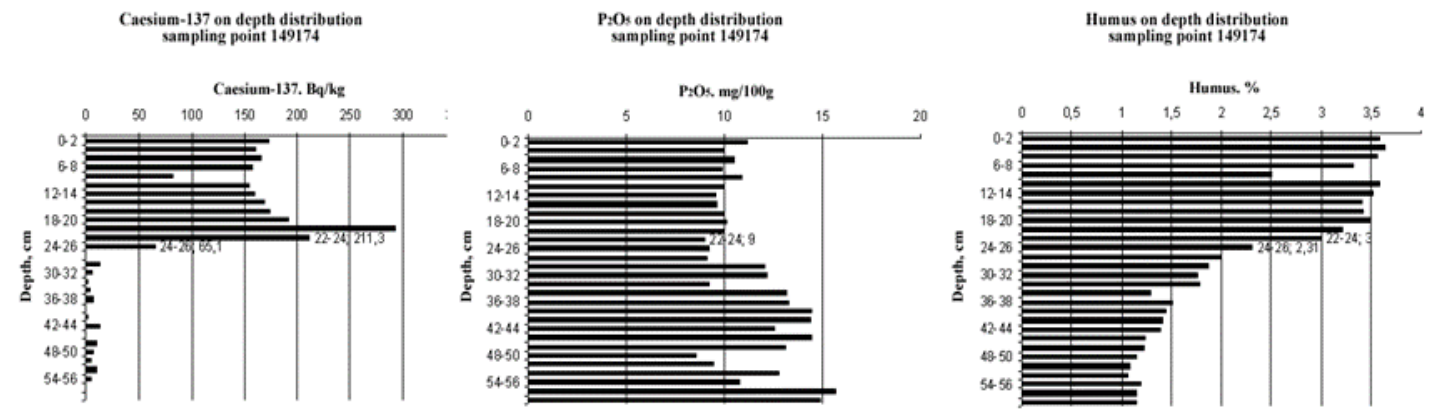

Figure 4. On depth distribution of caesium-137, P2O5, and humus at the sampling point 149174 (block elevation, unwashed soil)
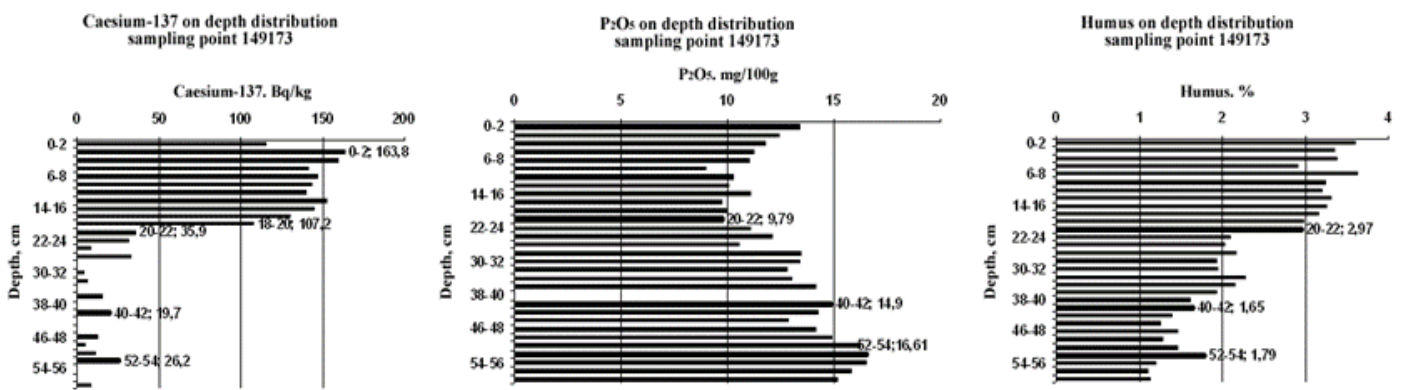

Figure 5. On depth distribution of caesium-137, P2O5, and humus at the sampling point 149173 (thalweg of the plowing furrow in the block elevation, slightly washed soil) 

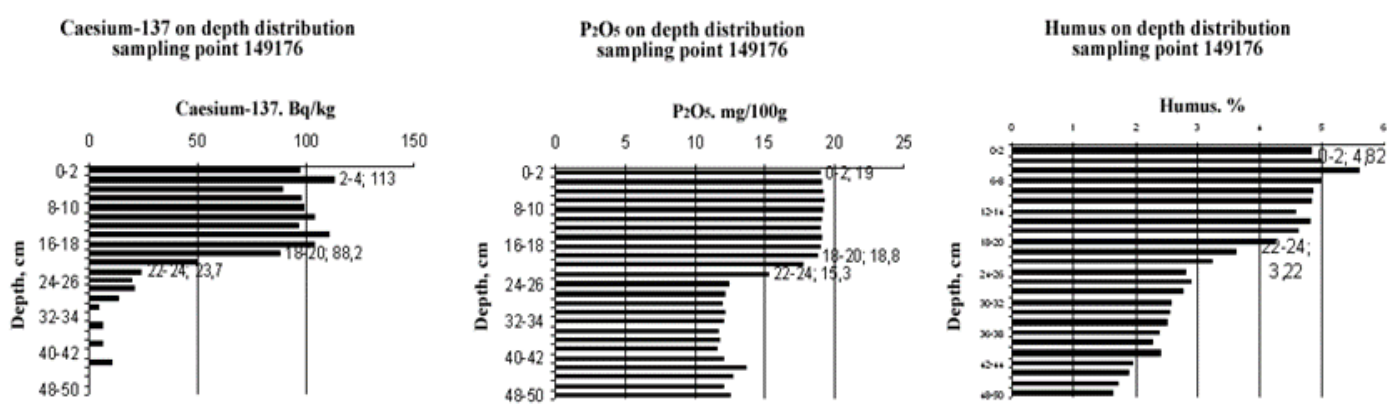

Figure 6. On depth distribution of caesium-137, P2O5, and humus at the sampling point 149176 (thalweg of the plowing furrow in the inter-block depression, medium-washed / washed-in)

Figure 4 shows low humus content (2.5-3.6\%) at the sampling point 149174 (block elevation), due to that the soil here is plowed-out. Humus, is carried out by plants and mineralized during agriculture use of the field (humus content in the arable soil layer is 3.5-3.6\%). The $\mathrm{pH}$ varies between 4.7-4.8 (the soil is slightly acidic). The specific radioactivity of caesium-137 in the $0-24 \mathrm{~cm}$ soil layer is $173.2 \mathrm{~Bq} / \mathrm{kg}$ (it indicates that the soil is unwashed). The plowing horizon is sharpen, located at the $24 \mathrm{~cm}$ on depth). Right above this horizon maximum value of caesium-137 radioactivity $(291.9 \mathrm{~Bq} / \mathrm{kg})$ is presented, due to the accumulation of soil moisture contaminated by caesium on the compacted surface of the horizon. Such a distribution of caesium-137 on depth (that is characteristic in the watershed surface) we also noted in previous studies [7]. The caesium-137 reserve in the $0-24 \mathrm{~cm}$ soil layer is $457248 \mathrm{~Bq} / \mathrm{m} 2(457.2 \mathrm{kBq} / \mathrm{m} 2)$. "Unrecorded" reserve in deeper soil layer (bellow $24 \mathrm{~cm}$ ) is insignificant (a little more than $5 \%$ ).

This sampling point can be used to establish the reference value of caesium-137. It is important to note that the point is located outside the plowing furrows. The caesium-137 and humus content decrease in the sub-plowing layer (starting from $25-26 \mathrm{~cm}$ ), while mobile phosphorus increases to $12.03 \mathrm{mg} / 100 \mathrm{~g}$ starting from $28 \mathrm{~cm}$ on depth. Its values increase to $15 \mathrm{mg} / 100 \mathrm{~g}$ and more on depths deeper than $56 \mathrm{~cm}$. Since the humus content on these depths is small (1-2.3\%), the increase of P2O5 can be explained by an increase of clay particles content in these layers. P2O5 (introduced with fertilizers) is released during denudation and interacts intensively with colloidal particles of clay minerals, its content increases under the arable soil layer. In the arable layer, decrease of mobile phosphorus content is explained by its release to the phytomass formation.

A small peak of P2O5 on $28-30 \mathrm{~cm}$ depth $(12.03 \mathrm{mg} / 100 \mathrm{~g})$ coincides with a small peak of caesium-137 content $(12.6 \mathrm{~Bq} / \mathrm{kg})$ on the same depth. It can be assumed that the vole mice carried and buried food residues from the surface through underground passages, and these residues produced small peaks of both caesium-137 (collected on soil surface) and organic origin phosphorus.

The mobile phosphorus content in the under-plowing horizon on a block elevation not corrupted by plowing furrows is slightly higher than $15 \mathrm{mg} / 100 \mathrm{~g}(56-58 \mathrm{~cm}$ soil layer in Figure 4), while a different situation is observed at the sampling point in the thalweg of plowing furrow in the block elevation (sampling point 149173 in Figure 5). Low value of humus content in the plowing layer (2.6-3.7\%) also indicates position of a sampling point in a block elevation. The radioactivity of caesium-137 in the arable layer is $140.5 \mathrm{~Bq} / \mathrm{kg}$. The soil here is plowed-out and slightly washed. The arable soil layer is "shortened" by $2-3 \mathrm{~cm}$ (its thickness is $22 \mathrm{~cm}$ ) accordingly to the humus-based estimations. The content of mobile phosphorus in the arable layer is $9.79-13.5 \mathrm{mg} / 100 \mathrm{~g}$ (higher than at the point 
149174). On a depth, the P2O5 increases to $16.61 \mathrm{mg} / 100 \mathrm{~g}$. This increase can be explained by the burying of crop residues in the plowing furrow.

The sampling point 149176 (Fig. 6) is located in a plowing furrow in inter-block depression. The soil here is a mid-washed/washed-in. Low specific radioactivity of caesium-137 in a $0-20 \mathrm{~cm}$ soil layer $(99.9 \mathrm{~Bq} / \mathrm{kg})$ indicates the soil as washed. Plowing brings the soil material from the lower horizons not contaminated with caesium-137, and it cause a low specific radioactivity of caesium-137 in the arable layer. The washed-in soil is indicated by the $19 \mathrm{mg} / 100 \mathrm{~g}$ and more P2O5 content in the soil layer above $24 \mathrm{~cm}$. This is higher than in the block elevation at point 149173. A sharp P2O5 decrease is observed on a $26 \mathrm{~cm}$ depth. Apparently, the washed in soil material and the buried (in the plowing furrow) crop residues caused the enrichment of the arable soil layer with phosphoric acid compounds and humus (to a 22-24 cm depth). A humus content is higher here than at the block elevation (3.7-4.82\%, to a $22 \mathrm{~cm}$ depth). $\mathrm{pH}$ value is higher than 5 (the alkaline soil nature is due to the enrichment of the soil with crop residues).

An increase of the mobile phosphorus content in arable soil layer may be observed instead of a decrease in a washed soil material in thalwegs, where a decrease of caesium-137 specific radioactivity indicates an increase of soil washout degree $(0-25 \mathrm{~cm}$ soil layer in Zone 5, Fig. 2). This interdependence coincides with the results obtained by Marusova [3]. It is also important to emphasize that Marusova concludes that the degree of soil erosion of cultivated gray soils can be estimated basin upon the content of mobile phosphorus in the arable soil horizon. Therefore, the caesium-137 can be considered as an appropriate marker of soil washout degree when studying the slope surface microrelief impact onto the soil nutrients loss (due to erosion). If the caesium-137 estimation can identify the loss of mobile phosphorus, it can recommended to be used in studies of the soil nutrient losses spatial distribution due to erosion.

\section{CONCLUSIONS}

The caesium-137 reserve does not exceed 4-10\% in the under-plowing soil layer (down to the bottom of Soviet-era arable layer $-30 \mathrm{~cm}[4]$ ), in the areas of unwashed and slightly washed grey forest soils in block elevations of the watershed surface.

The mobile phosphorus and humus content in the $0-25 \mathrm{~cm}$ arable soil layer is reduced due to the plowing-out of the soil, in the areas of unwashed and poorly washed soils confined to block elevations and to micro-watersheds (where the caesium-137 content increased). The caesium-137 content is reduced while mobile phosphorus and humus are increased due to the crop residues burying in the plowing furrow thalwegs in slightly washed soils of block elevations.

Increased humus and mobile phosphorus reserve are noted due to their introduction with washed in soil material and the influence of buried crop residues, in the washed soils of inter-block depressions intersected by plowing furrows where the caesium-137 content is low.

Two characteristic zones can be distinguished when zoning lateral distribution of mobile phosphorus along the slope. Humus and phosphorus values are low on the watershed surface (area of the block elevations not corrupted with plowing furrows) due to nutrients removal when harvesting and soil plowing-out, while the specific radioactivity of Chernobyl origin caesium-137 is high here.

Interdependence of the mobile phosphorus content and caesium-137 specific radioactivity (that indicates the degree of soil washout) is reversed at the slope base, where erosion furrows and plowing furrows corrupt the surface. It appears due to an increase of washed- 
in soil material amounts removed from the watershed surface along the ravine thalwegs, while it enriched with mobile phosphorus associated with colloidal particles of clay minerals.

Chernobyl origin caesium-137 can be used as a marker of soil washout, when studying the impact of erosion processes onto the variability of mobile phosphorus and humus content in the soil material. However, detailed study is necessary to estimate interdependences of caesium-137 and agrochemical parameters of gray forest soils differentiated in washout degree.

\section{Acknowledgement}

The publication was prepared with the financial support of the Russian Geographical Society.

\section{REFERENCES}

[1] Alifanov V.M., Gugalinskaya L.A., Ovchinnikov A.Yu. Paleocryogenesis and soils variety at the center of the East European plain. GEOS, 2010, 160 p. (In Russian)

[2] Costa-Cabral M.C., Burges S.J.. Digital Elevation Model Networks (DEMON): a model of flow over hillslopes for computation of contributing and dispersal areas. Water Resources Research, 30(6) , 1994, pp. 1681-1692. doi:10.1029/93WR03512

[3] Marusova E.A. Influence of natural and anthropogenic factors onto the properties of arable gray forest soils of the southern Moscow region. Thesis, PhD in biology, 2005, $147 \mathrm{p}$. (In Russian)

[4] Shamshurina E.N., Golosov V.N., Ivanov M.M. Spatiotemporal reconstruction of the Chernobyl 137Cs deposition field in the soil cover in upper Lokna River basin. Radiation Biology, Radioecology, 56(4), 2016, pp. 414-425.

[5] Trofimetz L.N., Chaadaeva N.N., Sankova E.A., Petelko A.I., Pryadunenko T.I. Soil losses on arable slopes of the Upper Oka valley against the background of climate change in the second half of the early 20th-21st century. Global Climate Change: Regional Effects, Models, Forecasts Proceedings, Russia, Voronezh, 2019, pp. 190-194. (In Russian)

[6] Trofietz L.N., Panidi E.A., Chaadaeva N.N., Sankova E.A., Ivaneha T.L., Petelko A.I. Estimation of soil loss in the thalwegs of natural-anthropogenic streams generated by heavy rainfall on arable slopes: application of satellite imagery, GIS and radiocaesium method InterCarto, InterGIS Proceedings, 25(2) , 2019, pp. 217-231. doi:10.35595/2414-9179-2019-225-217-231 (In Russian)

[7] Trofimetz L.N., Panidi E.A., Chaadaeva N.N., Sankova E.A., Ivaneha T.L., Tyapkina A.P., Petelko A.I., Alexandrova A.P., Ladnova G.G. Determing the reference value of Cesium-137 specific activity on arable slopes in the periglacial area of the Upper Oka basin: application of satellite images, GIS and soil agrochemical indicators. InterCarto, InterGIS Proceedings, 26(3), 2020, pp. 170-183. doi:10.35595/2414-9179-2020-3-26-170-183 (In Russian)

[8] Velichko A.A. Relict cryogenic morphosculpture of the Russian Plain, its scientific and applied significance. Reports of the USSR Academy of Sciences, 158(5), 2006, pp. 1078-1081. (In Russian) 